\title{
Self-Reported Treatment Adherence in Patients of Diabetes Mellitus Type 2: A Cross-Sectional Study in Lahore, Pakistan
}

\section{Sarah Rahman, ${ }^{1}$ Areej Asif, ${ }^{2}$ Mehwish Iftikhar, ${ }^{3}$ Amna Rizvi, ${ }^{4}$ Azhar Hussain ${ }^{5}$}

\begin{abstract}
Objectives: Suboptimal adherence to therapy due to neglected self-care behavior in chronic diseases is a global crisis. The aim of this research was to gauge the prevalence of adherence and to assess the effect of age, sex, education level and socioeconomic status on adherence to self-care strategies.

Methods: A cross-sectional study was conducted at Diabetes Management Centre, Services Hospital Lahore. 357 patients were administered a standardized questionnaire, the Diabetes Self-Management Questionnaire. A cut off value of 7 on a 0-10 scale was labeled as good adherence. The influence of age, sex, education and income on adherence was examined by multiple logistic regression analysis.

Results: The mean age of the sample was $49.76 \pm 12.5$ years, $64.52 \%$ were female, $37 \%$ had no formal education, and $47.39 \%$ had monthly household income $>$ Rs. 45000 . The prevalence of good adherence as a marker of good selfcare behavior was $42 \%$. The mean Sum Scale scores were 6.63 \pm 1.48 . Glucose Management subscale showed the highest mean score i.e. $6.65 \pm 2.07$ while Physical Activity subscale showed mean lowest score i.e. 5.26 \pm 2.75 . The sociodemographic factors being measured did not influence adherence significantly.

Conclusion: This study provides insight into the self-care behaviors of diabetic patients. This research highlights the immediate need to take steps to improve adherence among individuals. The sociodemographic factors were not found to influence adherence to self-care activities significantly in this sample. Further research is required to explore other factors that may increase the risk of suboptimal adherence among diabetics.

Key Words: Diabetes mellitus, adherence, factors, Pakistan

How to Cite: Rahman S, Asif A, Iftikhar M, Rizvi A, Hussain A. Self-Reported treatment adherence in patients of diabetes mellitus type 2: a cross-sectional study in Lahore, Pakistan. Esculapio.2020;16(04):22-28.

DOI: https://doi.org/10.51273/esc20.251645
\end{abstract}

\section{Introduction}

$\mathrm{O}^{-}$ ver last few decades, diabetes has emerged as a pandemic. From developed to developing nations, its prevalence is increasing rapidly, with approximately 463 million cases reported globally in 2019 and a projected rise to 700.2 million cases till 2045. In 2019 alone, it claimed 4.2 million lives. ${ }^{1}$

In recent years burden of diabetes has rapidly increased in both developed and developing countries. In

1. Sarah Rahman

3. Mehwish Iftikhar

5. Azhar Hussain

1-5: Services Institute of Medical Sciences, Lahore/Services Hospital Lahore

Correspondence:

Dr. Sarah Rahman, MBBS Student, Services Institute of Medical Sciences, Lahore/Services HospitalLahore.E-mail: sarah.rahman594@gmail.com
28-12-2020
2019, there were a dismal 19.4 million cases of diabetes and 159,000 diabetes related deaths in Pakistan. ${ }^{1}$

Diabetes is a chronic disease, and its management is a lifelong commitment. While a physician is responsible to draft a treatment plan, the onus of the execution is on the patients. $95 \%$ of the day-to-day management is carried out by the patient themselves, ${ }^{2}$ which means that between clinic appointments there is very little a physician can do. The efficacy of the treatment relies on the personal resolve of the patients alone.

Diabetes requires a complex, multifaceted treatment including lifestyle modifications, often as a first-line defense, and pharmacotherapy. The selfcare behaviors have several domains: blood glucose measurement, dietary control, exercise, medication and keeping appointments with the physician. The primary 
outcome is glycemic control i.e. maintaining $\mathrm{HbA} 1 \mathrm{C}$ at $<7 \%{ }^{3}$. Adherence to therapy is a significant predictor of treatment outcomes. ${ }^{4-6} \mathrm{WHO}$ defines adherence as: "The extent to which a person's behavior - taking medication, following a diet, and/or executing lifestyle changes, corresponds with agreed recommendations from a health care provider."7 Several international studies have shown adherence to be suboptimal. ${ }^{8-11}$ Regional research on this topic is limited, however non-adherence appears to plague patients in Pakistan as well. Studies conduc-ted in Karachi $^{12}$ and Multan ${ }^{13}$, for example, found only $20 \%$ of participants fully adherent. Non adherence leads to poor glycemic control ${ }^{6,14}$ and greater morbidity ${ }^{15}$. According to UKPDS 35, 1 percent decrease in HbAlc decreased risk of microvascular complications by $37 \% .{ }^{16}$ Predictors of non-adherence are classified as modi-fiable and unmodifiable factors. The latter include sociodemographic factors, including age, sex, educa-tion and socioeconomic status. $^{7}$ Literature provides conflicting reports on association of these factors with non-adherence, both national $^{12,17,18}$ and interna-tional..$^{11,19,20}$ These demographic characteristics can help physi-cians to forecast non-adherence in individuals. This can enable physicians to provide better attention to patients at risk of non-adherence and create personalized treatment plans for ideal outcomes. Local research on adherence is deficient, and to draw conclusions or comparisons a larger pool of data is required. In the present research, we attempted to determine the level of adherence in a local diabetic population sample and the effect of sociodemographic factors on adherence.

\section{Methods}

A cross-sectional questionnaire-based study was conducted at an urban government tertiary care institution, over a period of 1 month, from 1 st to $30^{\text {th }}$ of September 2019. Participants included in this study were older than 30 years, with a diagnosis of Diabetes Mellitus Type 2 for a duration of at least 1 year, who had received a full treatment plan from their health provider. Patients taking oral medication only, insulin only as well as combination therapy as a part of their treatment were included. Participants were chosen by convenience sampling and each gave informed consent to take part in the study. Exclusion criteria included the inability to understand Urdu, mental incapacitation and type I or gestational diabetes. The sample size selected for this study was 357 , for a confidence level of $95 \%$ and margin of error $\pm 5 \%$. The research involved the collection of two sets of data: the demographic characteristics of the population (Table 1), and the assessment of adherence. The demographic characteristics that were measured included age, sex, education and income as shown in Table 1. These were reported by the patient in a preliminary face-to-face interview. Treatment adherence was measured by a pre-valida-ted and reliable questionnaire (Cronbach's $\alpha=0.96$ ), the Urdu-version of Diabetes Self-Management Questionnaire (DSMQ) made by Schmitt ${ }^{21}$ et al and translated by Bukhsh et al. ${ }^{22}$ It was comprised of 4 sub-scales, namely Glucose Management, Dietary Control, Physical Activity and Health-care Use. ${ }^{21}$ There was one additional question relating to overall selfcare. Patients rated their adherence using a Likert scale of 0-3 to, where 0 was 'does not apply to me' and 3 was 'applies to me very much'. The sub-scale scores and sum scale scores were compiled separately and each was converted to a 0-10 scale. Adherence was considered as a dichotomous variable; a score of 7 or above was considered "good adherence". The DSMQ was administered in paper form and as an interviewer-assisted questionnaire. In the latter case, it was read out to the illiterate participants verbatim and no further description was provided, to ensure validity. Data was analyzed using SPSS 25.0. Prevalence of non-adherence in the population was calculated and represented as a percentage of the total population. Data was analyzed by multiple logistics regression analysis to forecast the trends and predict the association between the independent variables i.e. the demographic characteristics, and the dependent variable i.e. adherence. The results were adjusted for employment status, duration of diabetes, type of treatment and presence of comorbidities. Value of $p$ less than 0.05 was considered significant.

The purpose and components of the research were explained to each participant and informed consent was obtained. Ethical approval was obtained from the institution's ethical review board, Ref. No IRB/2019/ 570/SIMS.

\section{Results}

In September 2019, 357 patients were administered the DSQM at the Diabetes Management Center, SHL. 
The mean age of respondents was $49.76 \pm 12.5$ years. $231(64.5 \%)$ were female and majority i.e. $133(37.3$ $\%)$ of the respondents had no education. 168 (47.3 $9 \%$ ) respondents had income $>$ Rs. 45000 while 91 (25.49 \%) had income between Rs. 35001 to Rs. 45000. The demographic and clinical characteristics of the population are summarized in Table 1.

Good adherence to therapy (sum scale score $\geq 7$ ) was seen in $150(42 \%)$ participants. The mean sum scale score was $6.63 \pm 1.48$. Table 2 shows the mean scores for the individual sub-scales and sum scale; it also records the scores corresponding to the demographic variables. Sum scale scores were highest for 60-70 years age group followed by $>70$ years; 51-60 age group showed lowest scores. Females had higher scores than males, i.e. $6.67 \pm 1.26$ and $6.56 \pm 1.82$ respectively. There was an overall increase in the scores with an increase in the level of education. The lower income groups obtained higher sum scale scores.

Glucose management, Dietary and Healthcare Use sub scales showed increased adherence with increasing age. Physical activity sub scale showed the opposite. Males demonstrated better glucose management and health care use but poorer physical activity and dietary management scores. Higher education showed an overall better glucose management and physical activity scores. Those with middle school education showed highest health care use scores. Lowest dietary control and physical activity scores were observed in the FSc./Class ${ }^{11-12}$ category. Better physical activity scores were seen in higher income groups. In contrast there was a decrease in dietary control and health care use scores with an increase in income level. Glucose management was highest in lower income groups. Dietary control and physical activity were poor across all variables. Socio demographic factors affecting adherence are reported in Table 3. Good adherence was highest in 41-50 and 51-60 age groups. More males were adherent than females. $34.67 \%$ of the adherent individuals had no formal education. Good adherence was highest in highest income group. A multiple logistic regression model was used to predict the influence of the demographic characteristics on the dependent variable i.e. adherence. The $p$ values for all variables were greater than 0.05 and hence the variables were insignificant. The pvalues are reported in Table 3.

\section{Discussion}

Two out of five patients were found to have good adherence. This is a concerning statistic, as poor adherence is a major factor that contributes to poor glycemic control $^{8}$ and, consequently, complications ${ }^{24}$ and mortality. Suboptimal adherence is pervasive in previous litera-ture. A study conducted in Islamabad in 2015 reported $62 \%$ non-adherence in patients. ${ }^{17}$

Table 3: Demographic Profile of the Sample

\begin{tabular}{|c|c|c|}
\hline $\begin{array}{c}\text { Demographic } \\
\text { Characteristics }\end{array}$ & $\begin{array}{l}\text { Frequency } \\
\text { (n) }\end{array}$ & $\begin{array}{c}\text { Percentage } \\
(\%)\end{array}$ \\
\hline \multicolumn{3}{|l|}{ Age (years) $49.76 \pm 12.5$} \\
\hline $31-40$ & 59 & 16.53 \\
\hline $41-50$ & 132 & 36.97 \\
\hline $51-60$ & 117 & 32.77 \\
\hline $60-70$ & 35 & 9.8 \\
\hline$>70$ & 14 & 3.9 \\
\hline \multicolumn{3}{|l|}{ Gender } \\
\hline Male & 126 & 35.29 \\
\hline Female & 231 & 64.52 \\
\hline \multicolumn{3}{|l|}{ Education } \\
\hline No formal education & 133 & 37.25 \\
\hline Primary school/class $1-5$ & 52 & 14.57 \\
\hline Middle school/class 6-8 & 41 & 11.48 \\
\hline Matric/class 9-10 & 81 & 22.69 \\
\hline FSc../class 11-12 & 23 & 6.4 \\
\hline undergraduate & 27 & 7.56 \\
\hline \multicolumn{3}{|c|}{$\begin{array}{l}\text { Monthly household income } \\
\text { (Rs.) }\end{array}$} \\
\hline$<5000$ & 1 & 0.28 \\
\hline $5000-15000$ & 19 & 5.32 \\
\hline $15000-25000$ & 39 & 10.92 \\
\hline $25000-35000$ & 38 & 10.64 \\
\hline $35000-45000$ & 91 & 25.49 \\
\hline$>45000$ & 169 & 47.39 \\
\hline \multicolumn{3}{|l|}{ Employment } \\
\hline Employed & 117 & 32.77 \\
\hline Unemployed & 240 & 67.23 \\
\hline \multicolumn{3}{|l|}{ Locality } \\
\hline Urban & 242 & 67.79 \\
\hline Rural & 115 & 32.21 \\
\hline $\begin{array}{l}\text { Duration of diagnosis } \\
\text { (years): }\end{array}$ & $7.58 \pm 6$ & \\
\hline \multicolumn{3}{|l|}{ Type of treatment } \\
\hline Oral hypoglycemics & 166 & 46.50 \\
\hline Insulin & 125 & 35.01 \\
\hline Combination & 66 & 18.49 \\
\hline \multicolumn{3}{|l|}{ Co-morbidities } \\
\hline Yes & 240 & 67.23 \\
\hline No & 117 & 32.77 \\
\hline
\end{tabular}

The ENTRED study in France found suboptimal adherence to prescribed medications in almost $60 \%$ of the 3637 participants. ${ }^{25}$ A study in Kerala, India found $74 \%$ of the rural population to be nonadherent. ${ }^{26}$ Out of 257 patients in Karachi, 79.4\% were reported to have low adherence. ${ }^{12}$ A mere $20 \%$ of 
Table 2: Mean Scores and Standard Deviation of the Sub-scales and Sum Scale Across the Categories of Sociodemographic Variables. Mean Score of the Sample in each Subscale and Sum Scale is also Shown

\begin{tabular}{|c|c|c|c|c|c|}
\hline Demographics & $\begin{array}{c}\text { Glucose } \\
\text { Management } \\
\text { Sub-Scale }\end{array}$ & $\begin{array}{c}\text { Dietary } \\
\text { Control Sub- } \\
\text { Scale }\end{array}$ & $\begin{array}{c}\text { Physical } \\
\text { Activity Sub- } \\
\text { Scale }\end{array}$ & $\begin{array}{c}\text { Health-Care } \\
\text { Use Sub- } \\
\text { Scale }\end{array}$ & $\begin{array}{l}\text { Sum } \\
\text { Scale }\end{array}$ \\
\hline \multicolumn{6}{|l|}{ Age } \\
\hline $41-50$ & $6.47 \pm 1.97$ & $5.45 \pm 1.16$ & $5.35 \pm 2.48$ & $5.85 \pm 1.84$ & $6.54 \pm 1.40$ \\
\hline $51-60$ & $6.56 \pm 2.27$ & $5.41 \pm 1.35$ & $5.00 \pm 2.92$ & $6.02 \pm 2.29$ & $6.50 \pm 1.62$ \\
\hline $60-70$ & $7.07 \pm 2.34$ & $5.91 \pm 1.23$ & $5.75 \pm 3.04$ & $6.48 \pm 2.40$ & $7.10 \pm 1.47$ \\
\hline \multicolumn{6}{|l|}{ Gender } \\
\hline Male & $6.69 \pm 1.92$ & $5.47 \pm 1.51$ & $4.90 \pm 3.10$ & $6.61 \pm 2.73$ & $6.56 \pm 1.82$ \\
\hline Female & $6.63 \pm 2.33$ & $5.56 \pm 1.05$ & $5.45 \pm 2.53$ & $5.78 \pm 1.60$ & $6.67 \pm 1.26$ \\
\hline \multicolumn{6}{|l|}{ Education } \\
\hline No Formal Education & $6.46 \pm 2.23$ & $5.44 \pm 1.25$ & $5.05 \pm 2.67$ & $5.91 \pm 2.04$ & $6.53 \pm 1.50$ \\
\hline Primary School/Class $1-5$ & $6.72 \pm 1.75$ & $5.62 \pm 0.91$ & $5.34 \pm 2.58$ & $6.11 \pm 1.70$ & $6.74 \pm 1.10$ \\
\hline \multicolumn{6}{|c|}{ Monthly Household Income (Rs.) } \\
\hline$<5000$ & $8.33 \pm 0.47$ & $6.77 \pm 0.49$ & $5.00 \pm 2.56$ & $10.00 \pm 0.40$ & $8.13 \pm 0.59$ \\
\hline $5000-15000$ & $7.47 \pm 2.11$ & $5.77 \pm 1.57$ & $4.85 \pm 3.94$ & $8.01 \pm 2.61$ & $6.92 \pm 1.88$ \\
\hline $15000-25000$ & $7.47 \pm 2.25$ & $5.76 \pm 1.57$ & $5.13 \pm 3.48$ & $7.29 \pm 2.84$ & $6.92 \pm 1.89$ \\
\hline $25000-35000$ & $6.19 \pm 2.03$ & $5.32 \pm 1.34$ & $5.32 \pm 2.74$ & $6.11 \pm 2.14$ & $6.39 \pm 1.62$ \\
\hline $35000-45000$ & $6.27 \pm 2.12$ & $5.34 \pm 1.12$ & $5.08 \pm 2.50$ & $5.54 \pm 1.83$ & $6.41 \pm 1.35$ \\
\hline$>45000$ & $6.68 \pm 1.96$ & $5.57 \pm 1.12$ & $5.42 \pm 2.54$ & $5.81 \pm 1.70$ & $6.69 \pm 1.34$ \\
\hline Mean Score of the sample & $6.65 \pm 2.07$ & $6.39 \pm 1.71$ & $5.26 \pm 2.75$ & $6.08 \pm 2.10$ & $6.63 \pm 1.48$ \\
\hline
\end{tabular}

Table 3: Distribution of Frequency of Good Adherence Across the Categories of each Variable and Multiple Logistic Regression Significance Values. Comparison of Frequency of Good vs Poor Adherence in each Category is also shown.

\begin{tabular}{lccc}
\multicolumn{1}{c}{ Demographics } & $\begin{array}{c}\text { Good } \\
\text { Adherence } \\
\text { (n) }\end{array}$ & $\begin{array}{c}\text { p } \\
\text { Value }\end{array}$ & $\begin{array}{c}\text { Poor } \\
\text { Adherence } \\
\text { (n) }\end{array}$ \\
\hline Age & & .962 & \\
$31-40$ & 25 & & 34 \\
$41-50$ & 50 & & 82 \\
$51-60$ & 49 & & 68 \\
60-70 & 19 & & 16 \\
>70 & 7 & & 7 \\
Gender & & .674 & \\
Male & 97 & & 73 \\
Female & 53 & & 134 \\
Education & & .720 & \\
No Formal Education & 52 & & 81 \\
Primary School/Class 1 -5 & 23 & & 29 \\
Middle School/Class 6-8 & 19 & & 22 \\
Matric/Class 9-10 & 35 & & 46 \\
Fsc./Class 11-12 & 8 & & 15 \\
Undergraduate & 13 & & 13 \\
Monthly Household & & .684 & \\
Income (Rs.) & & & \\
$<$ 5000 & 2 & & 0 \\
5000-15000 & 11 & & 8 \\
15000-25000 & 19 & & 20 \\
25000-35000 & 15 & & 23 \\
35000-45000 & 36 & & 55 \\
45000 & 67 & & 101 \\
\hline
\end{tabular}

the population was found to be adherent at Nishtar Hospital, Multan. ${ }^{13} 45.4 \%$ of the sample at the rural health training center of Tamil Nadu showed low adherence, which is lower than that observed in our sample. ${ }^{23}$ Similarly, $42.3 \%$ were non-compliant in a study at Kolkata. ${ }^{27}$ However, most of these studies measured adherence using instruments different from that used in the present research, hence, comparison is difficult to make.

Lowest adherence was reported for physical activity, which is an observation reported frequently in literature. $^{27-29}$ The sample population showed better glucose management. Among the self-care behaviors measured glucose management, dietary control and health care use were found to be better in older individuals, which could be explained by the availability of family support as well as time. There was a decrease in the adherence to physical activity with increasing age, probably due to comorbidities which limit mobility. However, in the multiple logistic regression model, age was not a significant factor ( $p>0.05)$. Surveys at Islamabad, ${ }^{17}$ Tamil Nadu, India ${ }^{23}$ and France ${ }^{25}$ all demonstrated the effect of age on adhe-rence to be insignificant. A positive relationship has, however, been found in others. ${ }^{11,13,24,30}$ 
In this sample population males had better adherence to therapy; $64.71 \%$ of the adherent individuals were males. Males showed better healthcare use but poorer physical exercise levels, confirming the results of a Saudi Arabian study. ${ }^{31}$ Sex did not significantly modify adherence in our regression model. There have been mixed reports in the past regarding the association of sex with adherence. Some local ${ }^{13,17}$ and global studies $\mathrm{s}^{20,32,33}$ have shown similar results to ours. Others have commonly shown males to have better adherence. $^{11,30,34} 37.25 \%$ of the sample had no education, corresponding to the literacy statistics of Pakistan. ${ }^{35}$ This population scored lower in all selfcare activities. $34 \%$ of the adherent population had no formal education. The number of adherent vs nonadherent patients improved as the education level increased, however, there was no significant relationship found between the two variables. Researches at Aga Khan University Hospital, Karachi $^{28}$ and Rawal Institute of Health Sciences, Islamabad $^{17}$ demonstrated a neutral relationship. This was observed in Kenya ${ }^{8}$ and Tamil Nadu, India ${ }^{23}$ as well. Many regional surveys have found a positive relationship between education level and adherence, including studies at Quetta city, ${ }^{18}$ Islamabad $^{17}$ and Dhaka city, ${ }^{29}$ Bangladesh. The adherence for $<5000$ income group was seen to be unusually high, which could be due to the very small sample. $44.64 \%$ of the adherent patients earned Rs. 45000 or more, however this result could be influenced by the fact that almost half the patients belonged to this income group. The adherent and nonadherent patients in each income bracket, other than $<5000$, were approximately the same, indicating that income had no effect on adherence. Multiple logistic regression also confirmed this finding. Increase in adherence with better socioeconomic status has been overwhelming in past research. ${ }^{11,13,25,27,36}$ A neutral relationship has been observed as well, for example in Quetta city ${ }^{18}$ and Turkey, ${ }^{33}$ which agrees with the findings of this study. This study presented local data regarding adherence in patients of Diabetes Mellitus. It showed that over-all adherence is sub-optimal among patients, high-lighting the necessity to address this issue. The non-modifiable demographic factors were not predictors of adherence. There is an urgent need for further research to explore other factors that could impede adherence, so that targeted treatment strategies can be developed to combat non-adherence and improve glycemic control and treatment outcomes. The instrument was a self-reported questionnaire, which could lend a recall and social desirability bias, leading to underestimation of poor adherence. $^{37}$ However, self-reported questionnaires have been shown to be a reliable and convenient method to measure adherence related to clinical outcomes. ${ }^{38}$ Our results have been derived from a sample chosen by convenience sampling. This could impart some level of sampling bias to our results. However, our results agree with several regional and global which contributes to its credibility. This study was conducted in a central government tertiary care hospital, however, as the sample was chosen from only one institution, it may not be suitable to generalize these results to the national population.

\section{Conclusion}

This study provides insight into the self-care behaviors of diabetic patients. Patients were most diligent about glucose management. Adherence to physical activity was seen to be the lowest. The sociodemographic factors were not found to influence adherence significantly in this population sample. There is a strong need to carry out further research on the barriers to adherence to therapy in order to improve compliance, self-care behaviors and treatment strategies.

\section{Conflict of Interest: $\quad$ None}

\section{Reference}

1. Internation Diabetes Federation. IDF Diabetes Atlas, Ninth edition 2019. Dunia : IDF. 2019. 168 p.

2. Funnell MM, Anderson RM. The Problem With Compliance in Diabetes. JAMA. 2000 Oct 4; 284(13): 1709.

3. ADA. Diabetes Care American diabetes association standard of medical care in diabetes 2018. J cinical Appl Res Educ. 2018;1(January):94.

4. Cramer JA, Benedict A, Muszbek N, Keskinaslan A, Khan ZM. The significance of compliance and persistence in the treatment of diabetes, hypertension and dyslipidaemia: a review. Int J Clin Pract. 2008 Jan; 62(1):76-87.

5. Dimatteo MR, Giordani PJ, Lepper HS, Croghan TW. Patient Adherence and Medical Treatment Outcomes. Med Care. 2015 Sep;40(9):794-811.

6. Dalewitz J, Khan N, Hershey CO. Barriers to Control of Blood Glucose in Diabetes Mellitus. Am J Med Qual. 2000 Jan 3;15(1):16-25. 
7. Sabaté E. Adherence to Long-Term Therapies. Evidence for Action. Geneva; 2003.

8. Waari G, Mutai J, Gikunju J. Medication adherence and factors associated with poor adherence among type 2 diabetes mellitus patients on follow-up at Kenyatta National Hospital, Kenya. Pan Afr Med J. 2018 ;29.

9. Iglay K, Cartier SE, Rosen VM, Zarotsky V, Rajpathak SN, Radican L, et al. Meta-analysis of studies examining medication adherence, persistence, and discontinuation of oral antihyperglycemic agents in type 2 diabetes. Curr Med Res Opin. 2015 Jul 3; 31(7): 1283-96.

10. Farr AM, Sheehan JJ, Curkendall SM, Smith DM, Johnston SS, Kalsekar I. Retrospective Analysis of Long-Term Adherence to and Persistence with DPP4 Inhibitors in US Adults with Type 2 Diabetes Mellitus. Adv Ther. 2014 Dec 12;31(12):1287-305.

11. Kirkman MS, Rowan-Martin MT, Levin R, Fonseca VA, Schmittdiel JA, Herman WH, et al. Determinants of adherence to diabetes medications: Findings from a large pharmacy claims database. Diabetes Care. 2015 Jan 8;38(4):604-9.

12. Abbas A, Kachela B, Muhammad Arif J, Tahir KB, Shoukat N, Barkat Ali N. Assessment of medication adherence and knowledge regarding the disease among ambulatory patients with diabetes mellitus in Karachi, Pakistan. J Young Pharm. 2015;7(4): 32840.

13. Imtiaz S, Ullah H, Rasool MF, Hashmat F, Saleem M, Khan N, et al. Assessment of Compliance of Diabetic Patients At Nishtar Hospital Multan, Pakistan. 2014; 12(2) :84-8.

14. Krapek K, King K, Warren SS, George KG, Caputo $\mathrm{DA}$, Mihelich $\mathrm{K}$, et al. Medication adherence and associated hemoglobin A 1c in type 2 diabetes. Ann Pharmacother. 2004;38(9):1357-62.

15. Balkrishnan R, Rajagopalan R, Camacho FT, Huston SA, Murray FT, Anderson RT. Predictors of medication adherence and associated health care costs in an older population with type 2 diabetes mellitus: a longitudinal cohort study. Clin Ther. 2003 Nov; 25(11): 2958-71.

16. Stratton IM, Adler AI, Neil HA, Matthews DR, Manley SE, Cull CA, et al. Association of glycaemia with macrovascular and microvascular complications of type 2 diabetes (UKPDS 35): prospective observational study. BMJ. 2000 Aug 12; 321(7258): 405-12.

17. Shams N, Amjad S, Ahmed W. Drug Non-Adherence in Type 2 Diabetes Mellitus; Predictors and Associations. J Ayub. 2016;28(2):302-7.
18. Iqbal Q, Bashir S, Iqbal J, Iftikhar S, Godman B. Assessment of medication adherence among type 2 diabetic patients in Quetta city, Pakistan. Postgrad Med. 2017 Aug 18;129(6):637-43.

19. Senior V, Marteau TM, Weinman J, Genetic Risk Assessment for FH Trial (GRAFT) Study Group. Self-Reported Adherence to Cholesterol-Lowering Medication in Patients with Familial Hypercholesterolaemia: The Role of Illness Perceptions. Cardiovasc Drugs Ther. 2004 Nov;18(6):475-81.

20. Nau DP, Aikens JE, Pacholski AM. Effects of gender and depression on oral medication adherence in persons with type 2 diabetes mellitus. Gend Med. 2007;4(3):205-13.

21. Schmitt A, Gahr A, Hermanns N, Kulzer B, Huber J, Haak T. The Diabetes Self-Management Questionnaire (DSMQ): Development and evaluation of an instrument to assess diabetes self-care activities associated with glycaemic control. Health Qual Life Outcomes. 2013 Aug 13;11(1):138.

22. Bukhsh A, Lee SWH, Pusparajah P, Schmitt A, Khan TM. Psychometric properties of the Diabetes SelfManagement Questionnaire (DSMQ) in Urdu. Health Qual Life Outcomes. 2017;15(1):1-9.

23. Venkatesan M, Dongre A, Ganapathy K. A community-based study on diabetes medication nonadherence and its risk factors in rural Tamil Nadu. Indian J Community Med. 2018;43(2):72-6.

24. Jaam M, Mohamed Ibrahim MI, Kheir N, Hadi MA, Diab MI, Awaisu A. Assessing prevalence of and barriers to medication adherence in patients with uncontrolled diabetes attending primary healthcare clinics in Qatar. Prim Care Diabetes. 2018; 12(2): 116-25.

25. Tiv M, Viel JF, Mauny F, Eschwège E, Weill A, Fournier C, et al. Medication adherence in type 2 diabetes: The ENTRED study 2007, a French population-based study. PLoS One. 2012;7(3).

26. Sankar U V., Lipska K, Mini GK, Sarma PS, Thankappan KR. The adherence to medications in diabetic patients in rural Kerala, India. Asia-Pacific J Public Heal. 2015;27(2):NP513-23.

27. Mukherjee S, Sarkar BS, Das KK, Bhattacharyya A, Deb A. Original articlecompliance to anti-diabetic drugs: Observations from the diabetic clinic of a medical college in Kolkata, India. J Clin Diagnostic Res. 2013;7(4):661-5.

28. Malik S, Basit R, Naz S, Mawani M, Masood MQ, Akhter J. Adherence to Lifestyle Advice and Treatments in Pakistani Patients with Type 2 Diabetes Mellitus. J Diabetes Mellit. 2016 ;06(01): 49-57.

29. Mumu S, Saleh F, Ara F, Afnan F, Ali L. Non- 
adherence to life-style modification and its factors among type 2 diabetic patients. Indian J Public Health. 2014;58(1):40.

30. Curkendall SM, Thomas N, Bell KF, Juneau PL, Weiss AJ. Predictors of medication adherence in patients with type 2 diabetes mellitus. Curr Med Res Opin. 2013;29(10):1275-86.

31. Abdul Salam M, Farheen Siddiqui A. Sociodemographic determinants of compliance among type 2 diabetic patients in Abha, Saudi Arabia. J Clin Diagnostic Res. 2013 Dec;7(12):2810-3.

32. Bonafede MM, Kalsekar A, Pawaskar M, Ruiz KM, Torres AM, Kelly KR, et al. Insulin use and persistence in patients with type 2 diabetes adding mealtime insulin to a basal regimen: A retrospective database analysis. BMC Endocr Disord. 2011; 11(1): 3.

33. Serap T, Bayram Ş. Factors Influencing Adherence to Diabetes Medication in Turkey. Sch J Appl Med Sci Sch J App Med Sci. 2015;3(2A):602-7.

34. Hertz RP, Unger AN, Lustik MB. Adherence with pharmacotherapy for type 2 diabetes: a retrospective cohort study of adults with employer-sponsored health insurance. Clin Ther. 2005 Jul 1;27(7): 106473.
35. Government P. Pakistan Economy Survey 20152016. Education. 2015;169:192.

36. Kassahun A, Gashe F, Mulisa E, Rike WA. Nonadherence and factors affecting adherence of diabetic patients to anti-diabetic medication in Assela General Hospital, Oromia Region, Ethiopia. J Pharm Bioallied Sci. 2016;8(2):124-9.

37. Stirratt MJ, Dunbar-Jacob J, Crane HM, Simoni JM, Czajkowski S, Hilliard ME, et al. Self-report measures of medication adherence behavior: recommendations on optimal use. Transl Behav Med. 2015 Dec;5(4):470-82.

38. Nguyen T-M-U, La Caze A, Cottrell N. What are validated self-report adherence scales really measuring?: a systematic review. Br J Clin Pharmacol. 2014 Mar;77(3):427-45.

\section{Authors Contribution}

RS: Methodology, Literature Review, Data

Collection, Article Writing

AA: Data Collection

IF: Supervision, Methodology

RA: Drafting Revising, Analysis

HA: Methodology and Statistics 